Journal Homepage: $-\boldsymbol{w w w . j o u r n a l i j a r . c o m}$
ISSN NO. 2320-5407

RESEARCH ARTICLE

\title{
PREVALENCE OF TRANSFUSION TRANSMITTED INFECTIONS (TTI) IN OUR TERTIARY CARE HOSPITAL, KANCHIPURAM, TAMILNADU.
}

G.M.Thamilselvi ${ }^{1}$ and S.Senthamarai ${ }^{2}$.

1. Department of transfusion medicine,Meenakshi Medical College and Research Institute, Kanchipuram.

2. Professor, Department of Microbiology,Meenakshi Medical College and Research Institute, Kanchipuram.

\section{Manuscript Info}

Manuscript History

Received: 02 December 2018

Final Accepted: 04 January 2019

Published: February 2019

Key words:-

Seroprevalence, Transfusions transmittable infections, HBV, HCV..

\section{Abstract}

Background: Blood transfusion carries the major risk of transmitting infections such as hepatitis, HIV, syphilis, and malaria, which needs a proper and serious monitoring to provide safe blood for transfusion.

Aim: To determine the seroprevalence of Transfusion Transmitted Infections (TTIs) and to evaluate trends in TTIs among blood donors

Materials and method: The present study was carried out in Department of Transfusion medicine, Meenakshi Medical College Hospital, Kanchipuram. Study period was from January 2018 to December 2018. A total number of 1588 donors were screened for HIV, HBV, HCV, syphilis and malaria by ELISA method.

Results: Out of 1588 donors, $95.84 \%$ were males $4.16 \%$ were females. $1.008 \%$ were reactive for transfusion transmitted infection. HBV $0.94 \%$, and HCV $0.06 \%$ were the major infections in blood donors. None were positive for HIV, syphilis and malaria

Conclusion:Seropositivity of HBV, HCV, HIV, syphilis and malaria among the healthy donors indicates the risk or chance of acquisition of these infections during blood transfusion. Implementation of donor selection criteria should be strict and proper to minimize transfusion transmitted infections and provide safer blood and blood products and also higher generation kits and newer strategies are to be adopted.

Copy Right, IJAR, 2019,. All rights reserved.

\section{Introduction:-}

In every health care system, Blood Banks are an essential part to provide blood transfusion services which is required for the medical conditions like Anemia, Thalassemia, and Hemophilia, etc., or in surgical conditions, gynecological problems and any kind of blood loss. ${ }^{1}$ During the blood transfusion, transmission of infectious diseases through donated blood is an alarming situation and the causative agents can be virus, bacteria or protozoa. Globally, though blood transfusion saves the lives of millions of people, the transfusion transmitted infections (TTI) threaten the safety of patients for blood transfusion. ${ }^{1,2}$

Blood transfusion carries the risk of transmitting major infections such as hepatitis, HIV, syphilis, and malaria ${ }^{3}$. The World Health Organization (WHO) recommends all blood donations should be screened for evidence of infection prior to the release of blood and blood components for clinical or manufacturing use for the pursuit of global blood

\section{Corresponding Author:-S. Senthamarai.}

Address:-Department of Microbiology ,Meenakshi Medical College and Research Institute,

Kanchipuram. 
safety. After this routine serological screening implementation, the Transfusion-transmissible infections (TTIs) have been drastically reduced in many countries. ${ }^{4,5}$

Blood is one of the main sources of transmission of various TT pathogens. So donor selection is of paramount importance and the outcome of these infections range from subclinical asymptomatic to life-threatening manifestations. To prevent patients from acquiring TTIs, it is blood bank's responsibility and legal obligation by doing recommended testing before issuing blood and though these testing's are helpful to reduce TTIs, but not up to $100 \%$ as serological window period still poses a threat to blood safety. ${ }^{6}$

The aim of this study was to determine the prevalence of TTIs and to evaluate trends in TTIs among blood donors. This knowledge might give us an idea of burden of TTIs in blood donors and to know the basic epidemiology of these diseases in the community.

\section{Materials And Methods:-}

The present study was carried out in department of Transfusion medicine, Meenakshi Medical College Hospital, Kanchipuram. This 1 year Study was conducted from January 2018 to December 2018. A total number of 1588 donors were analyzed for the seroprevalence of Transfusion Transmitted Diseases.

Basic information regarding age, sex, occupation, address, marital status, number of previous donations and other relevant data's were obtained using donor form. Consent form and Donor Questionnaire was given in bilingual language to know about the health status of donor. Physical examination was done for all the blood donors before screening and blood donation. Donors having age less than 18 years and more than 60 years, weight <45 Kg, anemic, pregnant women, lactating women and current history of medication, recent history of having undergone a surgical procedure, serious illness, previous blood donation within 3 months were excluded from the study. After obtaining informed consent, blood was screened forHIV, HBV, HCV, syphilis and malaria by ELISAaccording to manufactures instructions.

\section{Results:-}

A total number of 1588 blood donations were taken during the period of January to December 2018 at department of Transfusion medicine at Meenakshi Medical College Hospital, Kanchipuram. In our study, Males outnumbered females with $1522(95.84 \%)$ donations while only $66(4.16 \%)$ donors were females (Table=1). Male female ratio was 23:1 for blood donation. $16(1.008 \%)$ were reactive for blood transmitted infection. In our study, HBV and $\mathrm{HCV}$ were the major infections in blood donors and the seroprevalence were $0.94 \%$, and $0.06 \%$ respectively. None were positive for HIV, syphilis and malaria. (Table-2)Most of the seropositive cases were between 20-30 years (Table-3)

Table 1:-Sex Distribution Of Donors

\begin{tabular}{|c|c|c|}
\hline $\mathrm{N}=1588$ & Total number of donors & Percentage (\%) \\
\hline Male & 1522 & 95.84 \\
\hline Female & 66 & 4.16 \\
\hline
\end{tabular}

Table 2:-Seroprevalence Of Tti

\begin{tabular}{|l|c|c|}
\hline $\mathrm{N}=16$ & Number of positive cases & Percentage (\%) \\
\hline HBV & 15 & 0.94 \\
\hline HCV & 1 & 0.06 \\
\hline HIV & 0 & 0 \\
\hline SYPHILIS & 0 & 0 \\
\hline MALARIA & 0 & 0 \\
\hline
\end{tabular}

Table 3:-Distribution Of Tti According To Age Group

\begin{tabular}{|c|c|c|c|c|}
\hline \multirow{2}{*}{$\begin{array}{l}\text { AGE IN YEARS } \\
\qquad(\mathrm{N}=16)\end{array}$} & \multicolumn{2}{|c|}{$\operatorname{HBV}(n=15)$} & \multicolumn{2}{|c|}{$\operatorname{HCV}(n=1)$} \\
\hline & $\mathrm{NO}$ & $\%$ & $\mathrm{NO}$ & $\%$ \\
\hline Less than 20 & 0 & 0 & 0 & 0 \\
\hline$<30$ & 11 & 73.3 & 0 & 0 \\
\hline
\end{tabular}




\begin{tabular}{|c|c|c|c|c|}
\hline$<40$ & 2 & 13.3 & 0 & 0 \\
\hline$<50$ & 1 & 6.7 & 1 & 100 \\
\hline$<60$ & 1 & 6.7 & 0 & 0 \\
\hline
\end{tabular}

\section{Discussion:-}

Blood transfusion is a lifesaving procedure and plays an important role in the supportive care and inevitable part of medicine.But globally, TTIs threaten the safety in recipients and the community which is of real concern.Seropositivity of HBV, HCV, HIV, syphilis and malaria among the healthy donors indicates the risk or chance of acquisition of these infections during blood transfusion. Screening for TTI ensures safe blood and blood product transfusion.

Among the donors, $95.84 \%$ were males and $4.16 \%$ were females. Male female ratio was 23:1 for blood donation in our hospital.

In line with our study, Male preponderance were reported in various Indian studies.In India, Garg Set al,Patelet al, and Bhagwan Singh Yadavet al, reported the percentages of $61.2 \%, 93.1 \%$, and 98\% respectively ${ }^{7,6,3}$. The similar rates were observed with the studies of Muhammad et al, Arshad et al, Yan Song et al andBedoya JAPet al, in other countries $1,2,5$, and 8 . Effort should be put to increase the number of female donors by various awareness programme.

In our study most of our positivedonors were between 20 to 30 years. The same has been observed withAsif $\mathrm{N} e t$ al,Arshad et al, and Bhagwan Singh Yadav et al,. ${ }^{9,2,3}$

The percentage of donor varies with place to place and time to time. $61.2 \%$ were voluntary donors $38.8 \%$ were replacement donors in the study of Fernandes et al, and $84 \%$ \& $16 \%$ were voluntary and replacement donors with Patel et al. ${ }^{10,6}$ The increase in voluntary donation could be attributed to education and the implementation of camps to raise awareness and to promote voluntary donation, carried out by blood bank staffs and National AIDS Control Organization (NACO) and other organizations.

The predominance of replacement donors was noted in the studies of Pahuja et al. (99.48\%), Bhagwan Singh Yadav

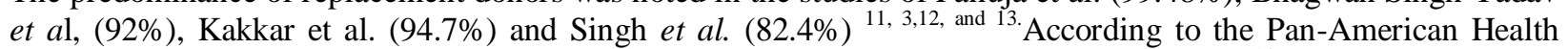
Organization (PHO), 67.78\% were replacement donations recorded in Latin America in $2009 .{ }^{14}$

The seroprevalence of TTI for the year 2018, was $1.008 \%$ in our study.Slightly lower seropositivity was reported by Fernandes et al., (0.6\%)andPatel et al $(0.72 \%)^{10,6}$. With the studies of Bhagwan Singh Yadav et al, (2.05\%), Yan Song et al(2.67\%),Bedoya JAPet al (3.3\%), and Aisha Arshad et al (5.8\%) ${ }^{3,5,8} 2$ reported high prevalence compared to our study. Prevalence of these TTI varies from place to place due variation in medical practices.

We observed $0.94 \%$ of Hepatitis B Viral (HBV) and $0.06 \%$ of Hepatitis C Viral (HCV) infections in our study. None of our donor showed seropositivity to HIV, syphilis and malaria.

In our study, the HBV seroprevalence is $0.94 \%$. Similar observation was made with the study of Shah Net al., at Ahmedabad (0.97\%). ${ }^{15} 0.06 \%$ of donors had Hepatitis C Viral (HCV) infections in our study. Patel et al at Gujarat, reported the similar seroprevalence of $\mathrm{HCV}(0.06 \%)$, which is concordant with our study. ${ }^{6}$

Though none were positive for HIV in this one year study, very low prevalence [0.08\%] has been reported with Chandra Tet al., at Lucknow.In a study conducted at Chennai, only one case was detected in HIV out of 25,000 donors in the past ten years. ${ }^{16,17}$

With many Indian studies, the seroprevalence of Syphilis range from $0.3-0.82 \%{ }^{18}$. But very lower percentage of syphilis was reported by Chandra T et al., [0.008\%] at Lucknow, Sethi B S et al., [0.02\%] at Uttarakhand. None of our samples were reactive for syphilis. ${ }^{16,19}$

In India, strategies followed to prevent the transmission of transfusion transmitted malaria are (a) Donors with fever (presumably malaria) in the last 3 months. (b) To screen the donated blood for presence of malarial markers ${ }^{20}$ In 
accordance with the study of Bhagwan Singh Yadav et al, S.T.Radhiga et al and Srikrishna et al, in our immunological screening test, all were negative for malaria ${ }^{3,17,21}$.

A low prevalence rate in our study may be attributed to strict screening criteria maintained in our blood bank.

\section{Conclusion:-}

To conclude, $1 \%$ of healthy donors are seropositive for TTI in this study and reveal the danger of transmitting through blood transfusion. HBV is the commonest TTI among apparently healthy blood donors, which is followed by HCV. Implementation of donor selection criteria should be strict and proper. To minimize transfusion transmitted infections and provide safer blood and blood products, highly generation kits and newer strategies are to be adopted.

\section{References:-}

1. Muhammad Kamran, Raja Tahir Mahmood, Muhammad Asghar Khan, AzharMehmood, LubnaNisar and M. JavaidAsad. Prevalence of Transfusion Transmitted Infections among Blood Donors; a Prospective Study. American Journal of Phytomedicine and Clinical Therapeutics: AJPCT[2][4][2014]540-543

2. Aisha Arshad, MuniraBorhany, Nida Anwar, Imran Naseer, Rehan Ansari, Samson Boota, Naveena Fatima, Mustansir Zaidi, Tahir Samsi. Prevalence of transfusion transmitted infections in blood donors in Pakistan, BMC Hematology (2016) 16:27

3. Bhagwan Singh Yadav, Amit V Varma, Prithviraj Singh, Rajesh Kumar, Prasann Kumar Bandi. Seroprevalence of transfusion-transmitted infections (TTIs) in blood donors: a study from central India. International Journal of Medical Science and Public Health | 2016 | Vol 5 | Issue 06:1158-62.

4. Chiavetta JA, Escobar M, Newman A, He Y, Driezen P, et al. (2003) Incidence and estimated rates of residual risk for HIV, hepatitis C, hepatitis B and human T-cell lymphotropic viruses in blood donors in Canada, 19902000. CMAJ 169: 767-773.

5. Yan Song, Ying Bian, Max Petzold, Carolina Oi Lam Ung. Prevalence and Trend of Major Transfusion Transmissible Infections among Blood Donors in Western China, 2005 through 2010. PLOS ONE | www.plosone.org : April 2014 | Volume 9 | Issue 4 | e94528

6. Patel P.J. Transfusion transmissible infections in blood donors: A [5] 7-year study in central Gujarat. Medical Journal of Dr. D.Y. Patil University. 2014; 7 (5):620-24

7. Garg S, Mathur DR, Garg DK (2001) Comparison of seropositivity of HIV. HBV, HCV and syphilis in replacement and voluntary blood donors in western India. Indian J Pathol Microbiol 44:409-412

8. Bedoya JAP, MónicaMaría Cortés Márquez,Jaiberth Antonio Cardona Arias. Seroprevalence of markers of transfusion transmissible infections in blood bank in Colombia. Infections in blood bank. 2012:46[6];950-59.

9. Asif N, Kokhar N, Ilahi F (2004) Seroprevalence of HBC, HCV and HIV infection among voluntary nonremunerated and replacement donors in northern Pakistan. Pak J Med Sci 1:24-28

10. Fernandes H, D'souza PF, D'souza PM. Prevalence of transfusion transmitted infections in voluntary and replacement donors. Indian J Hematol Blood Transfus 2010;26:89-91. B6

11. Pahuja S, Sharma M, Baitha B, Jain M. Prevalence and trends of markers of hepatitis C virus, hepatitis B virus and human immunodeficiency virus in Delhi blood donors. A hospital based study. Jpn J Inf Dis 2007;60:38991

12. Kakkar N, Kaur R, Dhanoa J. Voluntary donors-need for a second look. Indian J Pathol Microbiol 2004; 47:381-3.

13. Singh B, Verma M, Kotru M, Verma K, Batra M. Prevalence of HIV and VDRL seropositivity in blood donors of Delhi. Indian J Med Res 2005; 122:234-6. 7.

14. OrganizaciónPanamericana de la Salud. Suministro de Sangre para Transfusiones en los Paísesdel Caribe y de Latinoamérica 2006, 2007, 2008 y 2009: avancedesde 2005 del Plan Regional de SeguridadTransfusional. Washington (DC); 2010.

15. Shah N, Shah J.M, Javeeri P, Patel Kazoomi, Shah C.K, Shah [4] N.R. Sero prevalence of HBV, HCV, HIV and syphilis among blood donors at a tertiary Care Teaching Hospital in Western India. Gujarat Medical Journal. 2013; 68 (2): 35-39.

16. Chandra T, Rizvi N F and Agarwal D. Decreasing Prevalence of [3] Transfusion Transmitted Infection in Indian Scenario. Scientific World Journal. 2014: 1-4. Available from www.hindawi.com/ journals/tswj/2014/173939

17. S.T.Radhiga, P.Arumugam, S.Kalpana and MayilVahananNatarajan.Patterns of Transfusion Transmitted Infection in Past Ten Years Among Voluntary Blood Donors In Chennai- A Cross Sectional Study IOSR Journal of Pharmacy and Biological Sciences (IOSRJPBS). Volume 2, Issue 1 (July-August 2012), PP 01-04 
18. Suryatapa Saha, Prakash H Muddegowda, Thamilselvi Ramachandran, M. Joshua Daniel Jeyakumar, PoojithaDatla. Transfusion Transmitted Infection-An Update in India. National Journal of Laboratory Medicine. 2015 Oct, Vol 4(4): 77-82

19. Sethi B, Kumar S, Butola KS, Mishra J P, Kumar Y. Seroprevalence [6] pattern among blood donors in a tertiary health care center. Internet Journal of Medical Update. 2014;9(1):10-15.

20. Das A, Anvikar RA, Cator LJ, Dhiman R C, Eapen A, Mishra N et [28] al. Malaria in India: The center for the study of complex malaria in India. Acta Trop. 2012; 121:267-73 b 4= 28

21. Srikrishna A, Sitalakshmi S, Damodar P. How safe are our safe donors? Indian J Pathol Microbiol 1999;42:411$6 \mathrm{~B} 6=10$. 